\title{
Incorporating writing in advanced lab projects: A multiple case-study analysis
}

\author{
Jessica R. Hoehn $\odot^{*}$ and H. J. Lewandowski \\ Department of Physics, University of Colorado, 390 UCB, Boulder, Colorado 80309, USA \\ and JILA, National Institute of Standards and Technology and University of Colorado, \\ Boulder, Colorado 80309, USA
}

(Received 23 October 2020; accepted 1 December 2020; published 14 December 2020)

\begin{abstract}
Scientific writing, in the form of lab notebooks, proposals, and reports, is a common element of physics lab classes. Multiweek student-designed projects are growing in popularity, especially in advanced lab courses, and writing may play a unique role in these types of courses. In prior work, we developed a framework of possible goals for writing in physics lab classes. Here, we use that framework as a lens through which to view three different advanced lab courses that include student-designed projects. We conduct a multiple case-study analysis to investigate how these courses incorporate writing to address various goals. We find that both the timescale and the open-ended nature of projects present unique opportunities for having students engage in authentic writing practices.
\end{abstract}

DOI: 10.1103/PhysRevPhysEducRes.16.020161

\section{INTRODUCTION}

Writing plays a key role in the process of science, and as such is identified as an important skill that students should develop throughout their undergraduate physics curriculum [1]. Laboratory classes present ample opportunities for students to engage in scientific writing, and communication in some form is often included as an explicit goal of physics lab classes [2-4].

There are a variety of reasons instructors might incorporate writing in their lab courses [5]. Lab courses have been shown to improve students' conceptual understanding and attitudes towards science, through guided lab reports like the Science Writing Heuristic [6,7]. Others have demonstrated increased engagement and improvement of writing skills by having students communicate experimental physics to a nonphysics audience through the "Letter Home" alternative to a traditional lab report $[8,9]$. Writing in lab classes in particular can help students learn about, and engage in, realistic scientific practices such as keeping (and relying on) a lab notebook [10] or participating in a peer-review process [11]. Writing may also be the medium through which instructors teach students about the nature of experimental physics; for example, Eblen-Zayas implemented written reflections that helped normalize students' frustration in the lab and ultimately led to positive affective outcomes [12]. Here, we conduct an in-depth exploration of

*jessica.hoehn@colorado.edu

Published by the American Physical Society under the terms of the Creative Commons Attribution 4.0 International license. Further distribution of this work must maintain attribution to the author(s) and the published article's title, journal citation, and DOI. the possibilities for implementation of writing in lab courses with student-designed projects in order to address a variety of goals.

In prior work, we developed a framework to use as a tool for thinking about and understanding the role of writing in lab classes [5]. The framework defines fifteen possible goals instructors might have for writing in labs, organized into five overlapping categories-communication, writing as professionalization (WAP), writing to learn (WTL), course logistics, and social emotional. Here, we use this framework as a lens through which to view three different advanced lab courses that include student-designed projects. Multiweek student-designed projects are growing in popularity in lab courses [13]. Such projects have unique affordances when it comes to students' learning, including the possibility to engage in authentic communication practices $[1,13]$. We conduct a multiple case-study analysis on how writing is implemented in these courses in order to try to address various goals the instructors have for writing. The goals of this paper are the following: (a) present an indepth description of possible implementations of writing as a key element of student-designed projects, (b) demonstrate how the framework of possible goals for writing in lab classes [5] can be used for research, and (c) discuss the unique affordances of student-designed projects for writing.

\section{FRAMEWORK}

Here, we provide an overview of the fifteen goals and five categories that make up the framework of possible goals for writing in lab classes (Fig. 1). The framework was developed through interviews with four instructors of advanced lab classes and a review of literature on writing 


\section{Goals for writing in physics lab classes}

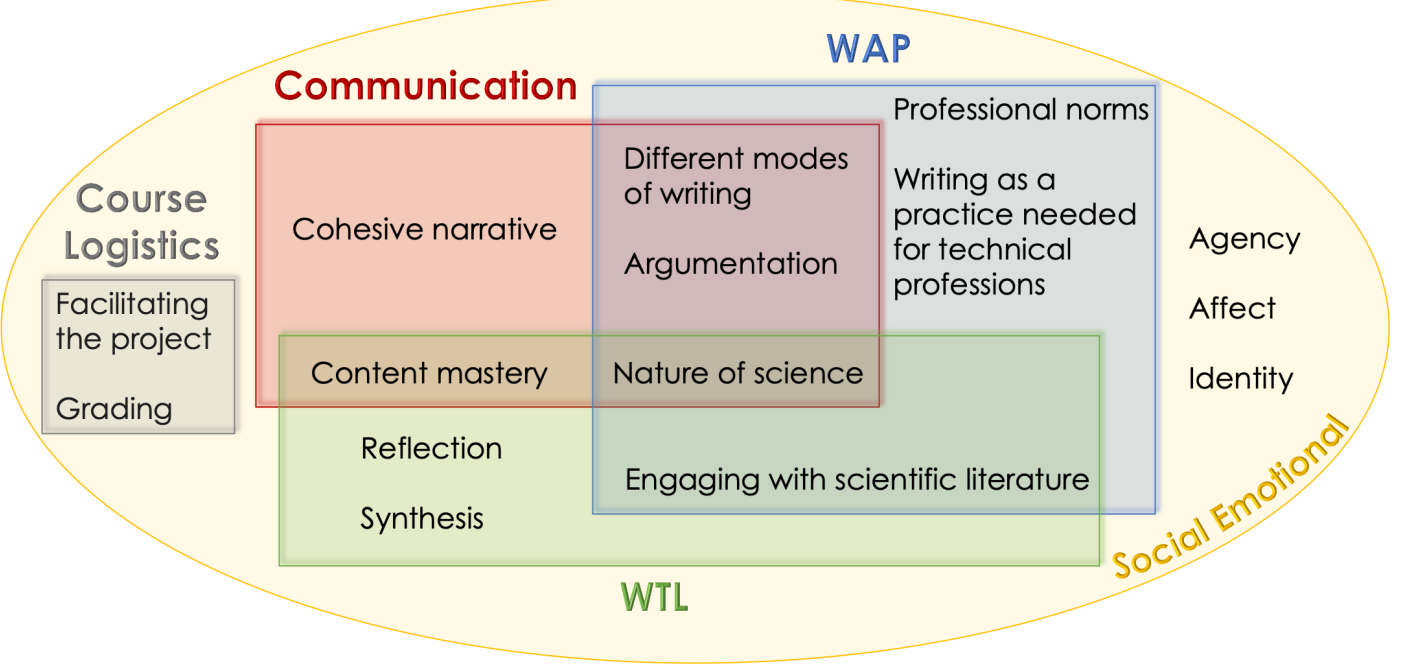

FIG. 1. Framework for thinking about and understanding the role of writing in physics lab classes. There are fifteen goals organized into five overlapping categories. Adapted from Ref. [5].

in science. For a more in-depth description of the framework and its development, see Ref. [5].

\section{A. Communication}

The communication category considers the primary purpose of writing to be for the writer to demonstrate to the readers what they did or what they know, focusing on the final product of a piece of writing rather than the process. Helping students learn how to communicate their work clearly and effectively is often included as an objective of physics lab classes [2]. The five specific goals in this category are about helping students develop general communication skills, independent of specific professional practices. Cohesive narrative refers to wanting students to learn how to write about an experiment with a coherent story, rather than presenting background, methods, results, etc., as being disconnected from one another. The different modes of writing goal refers to the desire for students to have the opportunity to practice different types of writing writing with different purposes for different audiences-for the sake of broadening their written communication skills. Argumentation refers to wanting students to improve their ability to write a clear and convincing argument. The different modes of writing and argumentation goals also exist in the WAP category when they are tied to particular modes and practices important to a scientific profession (see Sec. II B). The content mastery goal refers to wanting students to learn physics content through writing. Because writing can facilitate the process of, as well as be the medium through which students demonstrate content mastery, it exists in the overlap between communication and WTL. Lastly, the nature of science goal exists at the intersection of the communication, WAP, and WTL categories. For the sake of eliminating redundancy, we will discuss it in the following section.

\section{B. WAP}

The WAP approach emphasizes the importance of writing as something that is integral to the practice of science [14], having students communicate using "forms authentic to the discipline" [2]. The six goals in this category focus on practices, norms, and skills that will benefit students if they pursue a career in physics, or other related field. The different modes of writing goal refers to wanting students be able to write about experimental physics in multiple contexts, specifically highlighting modes of written communication that are central to the process of science (e.g., lab notebooks, proposals). Argumentation is located in the WAP category when instructors want students to learn how to write persuasively because being able to construct a convincing argument and convey it through writing is an important skill for a scientist. Further, the practice of argumentation in physics can be highly discipline specific, including justifying the validity of models used to describe a reliable dataset and then convincing an audience of claims supported by evidence [3]. One goal that many instructors have for writing in labs is for students to learn the professional norms of the discipline. This can include the style, format, and tone of writing, as well as conventions about what to include in an abstract, how to caption figures, and how to include references. The writing as a practice needed for technical professions is more general than the other goals in the WAP category. It focuses on writing practices or experiences that are key elements of many scientific and technical professions. Instructors who espouse this goal 
want students to learn about particular forms or processes of writing (e.g., peer review) as integral to the practice of science (or other related technical professions). Engaging with scientific literature refers to wanting students to develop the skills of being able to find, read, evaluate, and critique scientific literature, and then be able to situate their own project within a broader scientific community.

The nature of science goal straddles the three central writing skills categories (communication, WAP, WTL) and also connects several distinct goals from across the framework. We use the phrase "nature of science" to refer to the following: (a) beliefs about what it means to know and learn experimental physics, and (b) expectations about the process and practice of experimental physics. An instructor might incorporate writing in a lab class in order to help students see written communication as an important part of how scientific knowledge is generated (communication category). Writing may also be used to cultivate specific epistemological views that align with professional practice in the discipline (WAP category) — for example, implementing writing such that students come to see that scientific knowledge is generated through an iterative process. Lastly, instructors may include writing to help their students learn about methods of science or reflect on their own epistemic views about science (WTL category).

\section{WTL}

The WTL approach considers writing as a tool to facilitate thinking and learning, and focuses on the process of writing rather than the final product $[15,16]$. There are five goals in the WTL category. Content mastery, also appearing in the communication category, refers to wanting students to gain conceptual understanding of physics content or learn about the practices of experimental physics through engaging in writing assignments. Reflection refers to having students reflect on their own learning, their project, or the process of experimental physics through writing. The act of reflection is known to support learning in a variety of ways [12,17]. The synthesis goal hinges on the idea that the process of writing can help the writer make sense of ideas and connect disparate ideas or topics together. While the engaging with scientific literature goal exists in the WAP category because instructors might want their students to learn how scientists read and engage with literature, it also exists in the WTL category because instructors may want students to learn new physics content through reading physics journal articles. The nature of science goal is also present within the WTL category, as discussed above.

\section{Course logistics}

The course logistics category includes two practical reasons for incorporating writing in a lab class. Facilitating the project is a goal specific to courses with projects, where instructors implement writing in a way that encourages students to plan ahead and keeps students on track with their projects. The second goal is grading, which recognizes the fact that many instructors include writing, in part, because they need a way to assign students a grade. We suspect this goal is present in most classes that include some form of writing.

\section{E. Social emotional}

Writing, like any act of cognition, is a social activity situated within a particular context. The social emotional category is a recognition of the ways in which writing may support or facilitate students' personal experiences in the social environment of a lab course. There are three goals in this category, which include feelings or experiences that instructors might want students to have throughout the course of their projects. The social emotional goals underlie all the rest in the framework, and can both inform and be informed by the more writing skills related goals. Affect refers to the goal of many lab classes that students have a fun and positive experience with experimental physics; writing may be one way to facilitate these experiences, by helping students feel good about the completion of their work or supporting students emotionally through reflection. The agency goal refers to using writing as the medium through which students exercise and demonstrate their agency over, or their capacity to make decisions about, their own experiment. Lastly, many of our physics classes seek to support students' sense of identity as a physicist. The identity goal suggests that instructors may incorporate writing in order to help students come to see themselves as people who can participate in, and contribute to, the scientific community.

\section{METHODOLOGY}

\section{A. Case study approach}

Case-study methodology enables researchers to produce a holistic and in-depth understanding of a situation or phenomenon. Typically, this approach relies on extensive collection of data from multiple sources in order to construct a comprehensive description of the case [18]. In some situations, it is beneficial to include multiple cases in a single analysis in order to investigate multiple perspectives on a single topic. While case-study analyses cannot typically be generalized to a broad population or a wide variety of contexts, readers can identify from the case descriptions which elements of the particular context are similar or dissimilar to their own. As such, readers can determine for themselves to what extent the results may be generalizable to their own context (sometimes referred to as "user generalization" [19]). We take a descriptive multiple case study approach in order to investigate and understand possible ways to incorporate writing in advanced lab projects. In our study, there are three separate advanced lab classes (each at different institutions) that form three 
cases. Within each case, we triangulate across multiple data sources. In our analysis, we identify the ways in which instructors implement writing in order to attend to specific goals, and also identify cross-case themes. Three of the four original interviews that contributed to the development of the framework [5] form the three cases in this paper. Our analysis in this paper differs from prior analysis in that we identify implementation of writing as connected to various goals, and we triangulate among multiple data sources to form a holistic, in-depth understanding of the implementation of writing in these three courses.

\section{B. Data sources}

For our case-study analysis, we draw on three different data streams: instructor interviews, course materials, and monthly meetings with the instructors. After completing a term of teaching their advanced lab course, we interviewed each instructor about their goals for writing in the coursewhy do they include specific writing assignments and how do they implement them? The interviews provide a sense of the instructor's perspective about the role of writing in the course, as well as detailed information about their particular course structure and implementation of writing. We collected all relevant and available course materials from each case, including the syllabus, assignments, instructions or guidelines given to students, and rubrics. These materials provide evidence of goals for, and implementation of, writing, as well as the messaging to students about the purpose of writing as part of their projects. We facilitated monthly faculty online learning community (FOLC) meetings [20] with the three instructors partnering with us on the project. The goal of the FOLC was to provide a space where the instructors could share their approaches to teaching advanced labs, discuss challenges of including studentdesigned projects, and to support one another in their teaching. The meetings were recorded, and provide additional course context and implementation details, as well as documentation of any changes the instructors made or plan on making in the future. By facilitating the FOLC meetings, the first author built a relationship with the three instructors over the course of a year and, as such, gained an intimate understanding of their courses. This benefits our ability to provide a rich description of each case and conduct a holistic analysis.

All data used in this paper were collected between June 2019 and February 2020. While the COVID-19 pandemic impacted these courses in significant ways, those changes are not reflected in the present analysis. At one institution, there was turnover of instructors after the instructor interviews were conducted. As such, perspectives from four different instructors (two from one course) are included in our dataset. These instructors include one white woman and three white men. Specific institutional contexts are provided in the case descriptions below.

\section{Methods of analysis}

To begin our analysis, we first triangulated among all three data sources to write a description of each case (see Sec. IV below). We conducted member checks with each of the three instructors to ensure that our case descriptions were accurate and resonated with their experiences. The member checks resulted in only a few minor changes to details about the courses. From the case descriptions, we determined how writing was situated within the projects and course as a whole and identified goals for writing indicated by the overall course structure. Next, we conducted a coding analysis on the instructor interviews to identify specific goals and categories from the framework that were present in each case (for details on the codebook, see Ref. [5]). We did not count codes applied within or across cases, since the goal was not to make claims about how often a given instructor talked about a particular goal. Instead, we used the presence of codes to identify specific goals and specific writing assignments used to address those goals. Next, we reviewed the course materials available for each case and identified the categories and goals from the framework that were conveyed (explicitly or implicitly) in the text. Lastly, we used a data log of the recorded FOLC meetings to identify portions of conversations where the instructors shared information about their implementation of writing. We used the FOLC data to fill in any gaps in our understanding of the courses or the implementation of writing. In presenting the analysis, we include direct and paraphrased quotes from all three data sources to provide direct evidence of how writing is implemented during the projects in order to address specific goals.

\section{CASE DESCRIPTIONS}

In this section, we describe each of the three cases, particularly focusing on the role that writing plays in the projects and on how various writing assignments are implemented. Table I provides an overview of the writing assignments present in each course.

\section{A. Case 1}

Institution 1 (I1) is a small, predominantly white, private liberal arts college in the midwestern United States. For this case study, we look at a 10-week advanced laboratory course typically taken by physics majors in their junior or senior year. The class meets for $3.5 \mathrm{~h}$ plus one $4 \mathrm{~h}$ lab period per week. There are three instructor-designed labs that take two weeks each, and the remaining four weeks of the term are dedicated to student-designed final projects. The three instructor-designed labs include metal characterization using a Gouy balance, signal processing, and a single photon avalanche detector. The $3.5 \mathrm{~h}$ of class time are used for minilectures, group activities, and discussions that accompany the labs (e.g., discussions of good lab 
TABLE I. Implementation of writing in each of the three cases. Each cell indicates whether a given writing assignment is included for each case. "Group" indicates the writing is completed by a group of students, and "individual" indicates that each individual student turns in their own assignment.

\begin{tabular}{|c|c|c|c|}
\hline Type of writing & Case 1 & Case 2 & Case 3 \\
\hline Lab notebooks & Group, electronic & Individual & Individual \\
\hline Reflections & $\begin{array}{l}\text { Individual, } 7 \text { different prompts } \\
\text { throughout the term }\end{array}$ & & \\
\hline White papers & & & Individual, half are "funded" \\
\hline Proposals & Group & Group & $\begin{array}{l}\text { Funded and nonfunded pair, } \\
\text { includes written proposal } \\
\text { and oral presentation }\end{array}$ \\
\hline Peer review & Of proposals & Of each of the 3 lab reports & $\begin{array}{l}\text { Of white papers and proposals, } \\
\text { includes written comments } \\
\text { and in-class discussion }\end{array}$ \\
\hline Letter to the editor & & For each of the 3 peer reviews & \\
\hline Lab reports & $\begin{array}{l}3 \text { instructor-designed labs }+ \\
\text { final project, } \\
\text { first as a group, rest are individual, } \\
\text { in the style of a journal article }\end{array}$ & $\begin{array}{l}2 \text { instructor-designed labs }+ \\
\text { final project, } \\
\text { individual, in the style } \\
\text { of a journal article }\end{array}$ & \\
\hline
\end{tabular}

notebook keeping practices, or lessons on error analysis), though during the final project portion of the course, all the class time is used for working on the projects. Students work in groups of 2 to 3 , which are assigned by the instructor at the beginning of the term and remain the same throughout the class. The course typically enrolls between 10 and 25 students. When we partnered with John (pseudonym, he/him) for this research project, he had just taught this course for the first time, continuing several research-based reforms that the prior instructor had implemented and refined.

The course objectives, as stated in the syllabus, are that students will be able to

- "Evaluate the quality of measured data and compare measured data with predictions from a model or from previous work;

- Collaborate with peers to build or assemble a measurement system from a given set of components, test and revise the measurement system if it does not work as expected, and keep a clear record of your work as you do this;

- Clearly and convincingly communicate experimental work and results to an appropriate audience, either orally or in writing;

- Demonstrate the ability to be reflective on the practice of experimental physics."

As a core element of the class, the final projects are intended to address each of the above goals. Additionally, the instructor elaborated in the interview that a primary purpose of the final projects is for students to have the experience of proposing and carrying out their own specific experiment, including especially iterating and revising it as they progress. Examples of projects that students have completed in the course include measurement of the quantum efficiency of a silicon photodiode, construction of a Michelson interferometer for sound wave detection (modeled after LIGO), and an investigation of the properties of photovoltaic cells using alpha and beta sources. Students often consult with other professors in the department who specialize in the topics or skills necessary for their project.

There are several writing assignments woven throughout the course, for both the instructor-designed labs and the student-designed final projects, including lab notebooks, reflections, lab write-ups, final project proposal, peer review, and a final project paper.

Each group of students keeps an electronic lab notebook (ELN) for the three instructor-designed labs as well as the final project. The expectation is that all students in the group will share the documentation duties equally. At the beginning of the term, the instructor provides students with historical examples of lab records (e.g., Einstein's notebook) and facilitates a class-wide discussion of good and bad lab note keeping practices. Through this discussion, the class collectively creates a rubric that is then used to evaluate their notebooks throughout the term. Subcategories of the rubric include placing work in context, clear description of work done, diagrams, sketches, tables, reflection on the process, and organization. Since the notebooks are electronic, the instructor can check them at any time to monitor student progress, which is particularly important during the final project portion of the class. Students receive feedback from the instructor on their notebook at the end of each lab, and the lab notebook grade accounts for $15 \%$ of the total grade.

Throughout the course, students have to complete several short reflective writing assignments. The syllabus introduces the importance of these assignments by stating that "In a laboratory environment that includes open-ended problem solving, studies have shown that encouraging 
metacognition (thinking about ones own thinking) can improve learning." There are a variety of prompts that ask students to reflect on their own experiences with experimental physics - reviewing the AAPT recommendations for undergraduate lab learning outcomes [2] and identifying their own personal areas of confidence and areas that need strengthening, identifying challenges they have encountered in the lab and immediate goals, reflecting on what they learned from working with a particular apparatus, and reflecting on how their written communication skills improved throughout the class. The students complete seven reflections throughout the 10-week term; they make up $10 \%$ of the total grade.

Each of the three instructor-designed labs culminate in a formal lab write-up - the first one is written as a group and the other two are completed individually. These formal reports are intended to mirror real scientific papers, with the same tone and level of detail. At the beginning of the term, they spend one class period reading and discussing a contemporary experimental physics paper (e.g., published in the American Journal of Physics). The instructor facilitates a discussion about what was done well and not so well, which helps students understand the expectations for their own papers. Students receive feedback from the instructor on each of the papers, and at the end of the term they choose one of the three to rewrite based on the feedback they received. Each lab report accounts for $10 \%$ of the total grade.

To begin the projects, the students write a project proposal as a group that, as stated on the syllabus, is expected to contain background information, connections to previously published work, and an argument (as one might see in a funding proposal) for why the proposed project is worth doing. The proposals are meant to be 4-5 pages in length, and mimic a real scientific proposal. They must identify a specific research question, situate the work within established literature on the given topic, and have a well-described plan. These expectations are communicated to the students through a rubric used to evaluate the proposals. As part of the proposal process, students engage in peer review. Within each group, every student receives a proposal to review from a different group, such that the group collectively gains a sense for the span of other projects and proposals. Upon receiving comments from their peers, each group revises their proposal. Students are evaluated both on their own group's proposal and on their individual contributions as a peer reviewer. The final project proposal accounts for $10 \%$ of the final grade.

Each individual student writes a final paper about their project, which accounts for $15 \%$ of their overall grade. Much like the reports for each of the instructor-designed labs, the final project paper is meant to be written in the style of a scientific journal article. Students also create and present a final poster as a group, but this mode of communication is not included in our analysis.

\section{B. Case 2}

Institution 2 (I2) is a large, inclusive, public, master's degree granting, Hispanic serving institution in the Western United States (though the physics program only offers a bachelor's degree). The course we investigate for this case study is a 10-week advanced lab course typically taken by senior physics majors; it is offered in both the winter and spring quarters, and has a maximum capacity of 12 students per term. There are no intermediate labs offered in the physics curriculum, so this is the first and only lab class students will take after the introductory-level labs. The class meets for two 4-h lab periods per week. The syllabus states that the course is a "culminating laboratory course designed to introduce physics students to advanced instrumentation, quantitative analysis, and realistic forms of communication used in physics and other scientific disciplines." It also states that this course varies significantly from prior lower-division labs the students will have encountered in that it emphasizes developing good scientific procedures in planning, conducting, recording, and reporting the results of experiments."

Students work in groups of 2 to 3 throughout the course. In the first two weeks, all groups complete a lab in which they determine the magnetic permeability constant $\left(\mu_{0}\right)$ using a current balance. The next three weeks are used for a free choice project in which groups can choose one out of four experiments (e.g., scanning probe microscopy, x-ray diffraction). The last five weeks of the class are dedicated to student-designed projects in which the groups propose, design, and carry out their own experiment. In addition to the two labs and final project, the course includes homework assignments on error analysis using Taylor's textbook [21].

The instructor that we partnered with for this research project is Megan (pseudonym, she/her). She has taught this course several times, making incremental changes each time. Megan has modified the course to include fewer labs, more time for the final project, and a heavier emphasis on writing, stating "I didn't think there was a lot of time for reflectiveness [in the prior course structure]." At the time these data were collected, the university was in the process of transitioning from a quarter to a semester system. With that change, the department is restructuring their curriculum to include two semesters of upper division labs, both of which will satisfy the university's requirement for a "writing intensive" course. This, in addition to Megan's belief that writing is an important element to include in the course (self described as being "big into writing and science communication"), informs the way writing is woven throughout the class.

In the interview, Megan described her goal for the projects as giving students an "authentic science or physics experience" where they can synthesize and use all of the tools they have developed across the physics curriculum in a capstone project that is reflective of the things they will 
have to do after they graduate. To that end, there are several writing assignments included in the final projects. Examples of projects that students have completed in the course include building and characterizing a reverse-biased LED photon detector, using optical pumping to determine the cross-sectional area of rubidium absorption, and exploring the chaotic behavior of a dripping faucet.

Students keep individual, hard-copy lab notebooks throughout the course. At the beginning of the term, the instructor spends a few minutes in class talking about guidelines for good notebook practices. At the end of each lab session, the instructor checks that each student has completed a notebook entry for that day (this also accounts for attendance, which is required). Additionally, a few times throughout the quarter, students notebooks are collected and evaluated for both formatting and content (including experimental diagrams, equipment settings, procedures, raw data, graphs, and analysis and conclusions). Lab notebooks account for $10 \%$ of the total grade.

To begin the final projects, groups must come up with an idea and write a project proposal as a group. The proposal is short (maximum of two pages) in order to manage workload, since it coincides in the course schedule with a final report for the free choice project. To help students understand the expectations for proposals, Megan gives them a few examples of her own successful research proposals. The proposals are intended primarily to make sure students have thought through their project ahead of time, and thus they are not graded thoroughly. As a whole, the final project accounts for $45 \%$ of the total grade; the proposals account for $10 \%$ of the final project grade.

For each of the experiments (current balance, free choice, and final project), students write individual lab reports. At the beginning of the term, the instructor gives a short lecture about what makes a good lab report, using a few high-quality reports from prior students as examples. A document of guidelines for writing lab reports details the different sections that should be included in the report and the content of each section, based on how the instructor typically writes journal articles. In this document, Megan stresses that the exact format and headings are not important, stating, Overall I am more concerned about professionalism and that your report has all the relevant details needed to clearly understand your experiment and interpret your results. These expectations are also communicated to students via a thorough rubric, which was originally developed by students in this class who attended an extra credit workshop at the end of term. The lab reports are evaluated using this rubric, and account for an increasing amount of the overall grade as the term progresses. The current balance lab accounts for $10 \%$ of the overall grade, and $90 \%$ of that is the report. The free choice project accounts for $20 \%$ of the overall grade, and $60 \%$ of that is the report. The final project accounts for $45 \%$ of the total grade, and $40 \%$ of that is the final report.
A peer-review process accompanies each of the three lab reports. Each student reviews two papers from (anonymous) peers and is expected to write comments or annotations on the actual paper, as well as prepare a report that summarizes the manuscript and assesses the background and theory, technical quality and scientific rigor, presentation, and content and quality of appendix material. Before the first peer review, the instructor gives a short lecture about the peer-review process and what goes in a good peer review, including high quality examples from prior students. She also gives students guidelines to assist them in conducting their reviews and preparing their reports that she adapted from the Physical Review Letters reviewer guidelines. The first peer review (for the current balance lab) is completed during class time, but the other two are completed on students own time. Students are graded on the quality of their reviews, and for each of the three experiments, peer review accounts for $10 \%$ of the overall project grade. Once students receive comments from their peers, they must revise their paper and submit the final draft along with a letter to the editor. The instructions explain this process as follows: Whenever you revise a manuscript after peer review, you resubmit it to the journal with a letter to the editor. This letter not only details the changes you made to the manuscript, but why you made them and how they address specific parts of the reviewer reports. The instructor also provides an example of a review she has received for a manuscript along with her response.

\section{Case 3}

Institution 3 (I3) is a large, private, predominantly white, doctoral degree granting research university in the Western United States. The advanced physics lab course typically enrolls 20 junior physics majors, split into two sections. The 15-week semester consists of two lab rotations and a student-designed final project. The class meets for two three-hour lab periods per week, though sometimes during the projects students come in early or outside of class time to work on their projects. Each semester, the course is cotaught by two instructors, each teaching one section. Our data collection for this case study is split between two different instructors who taught the course in different semesters. The first instructor we partnered with, Tanner (pseudonym, he/him), participated in the interview. Shortly thereafter he left to take a position at a different university, and a second instructor, Matthew (pseudonym, he/him), took his place teaching the advanced lab course. Matthew participated in the monthly FOLC meetings and assisted us with data collection in the course. Thus, our case description and analysis draw on both Tanner and Matthew's perspectives. While they may have slightly different goals or approaches, both have taught the course multiple times and represent the goals and implementation of the course overall. 
There are four main objectives of the course, as stated in the syllabus:

- "Demonstrate the use and assembly of experimental systems important in physics using contemporary instrumentation components to perform experiments in areas such as coherent optical systems, microfabrication, and vacuum systems;

- Independently design and carry out multiperiod indepth projects;

- Learn (through the final project) about proposal writing, evaluation, and selection;

- Present research results through oral presentations." Both the lab rotations and the final projects are intended to address these course goals. The two rotations are vacuum and high voltage and microfabrication and optics, and each requires students to assemble an experiment to carry out a simple project. The syllabus explains to the students that, "unlike many other lab courses, these projects are not prebuilt, pretested, or error-free (welcome to the real world). The goal is not the projects, but the path and the tools to get there and the preparation and logical thinking so the projects work." Students work in groups of 2 to 3 on the lab rotation projects.

Attending to all of the objectives of the course, the goal of the final project is for students to demonstrate the scientific techniques and critical thinking that [they] have developed throughout the semester, as communicated to students in a document outlining the final projects. This document also states that the final project is intended to help you learn how to identify, design, execute, and sell your ideas within a scientific community. In the interview, Tanner synthesized these specific goals and said that the overarching purpose of the final projects is to prepare students to conduct research. Examples of projects that students have completed in this course include phonon scattering in a quartz crystal using Raman spectroscopy, acoustic levitation of water as a model for separating blood cells, and investigation of temperature effects on LED color and output.

The actual final project experiments are carried out in the last few weeks of the semester, but students begin thinking about their projects and preparing to conduct the experiments early in the semester (e.g., they submit a possible topic and title in week 3 or 4). Aside from lab notebooks, which are used throughout the entire course, all of the writing incorporated in the class is part of the project preparation process, through white papers and project proposals. Every student selects a topic of interest and writes a "white paper" to propose their own experiment. The white paper is framed for students as a preproposal that some funding programs will require you to submit as a way to narrow down the projects they are interested in without requiring the researchers to put the effort into creating a longer proposal or the reviewers to examine a longer, more detailed proposal. In 200-300 words, students are expected to describe the question they will answer (or problem they will solve), what they will measure, how they will take measurements, the challenges they anticipate, and the equipment they will use. As part of the introduction to the white paper process, instructors typically share examples of good and bad white papers with students.

Once the students have submitted their individual white papers (without names attached), they engage in a peerreview and panel-discussion process. Every student reviews three white papers from the other section of the class, rates them as don't fund, fund, or must fund, and ranks them against each other. Students bring these ratings and rankings to an in-class discussion where each student presents a summary of one paper and the class discusses whether it is convincing, interesting, relevant, and feasible. The class then votes on which projects should be selected. Taking the class discussions and students votes into account, the instructors select half of the proposed projects to receive "funding" (i.e., they get to go forward with the experiment). Funded and nonfunded students team up in pairs to carry forward the funded projects.

Each team first gives an oral presentation of the proposed project. To ensure that both students are invested in, and have ownership over, the project, the student who did not write the white paper that was funded is in charge of giving the presentation and responding to questions. The instructors comment that this structure helps ensure that all students have a good experience with the projects, even if their original proposed idea was not "funded." Following the presentation, each group submits one written proposal. The proposal is intended to expand on the white paper and ensure that the students are prepared to conduct the experiment. Proposals are 400-600 words, and beyond the information included in the white papers, they must include a detailed list of equipment or resources (and how the students plan on accessing them), as well as a timeline for the project. The proposals are also peer reviewed (in the same manner as the white papers, but without the in-class discussion), and the students have a chance to address reviewer feedback before submitting their final proposal and beginning to carry out the project. White papers and final proposals are evaluated according to the same rubric, which includes the criteria of a well thought out and feasible plan, organization, content, tone, format, resources, and timeline.

The overall goal of the white paper and proposal process is communicated to students in a guidelines document: The purpose of these activities is to give you practical experience in presenting a scientific plan in a way that is accurate, clear, and convincing. It will also give you insight into how the scientific funding process works. In addition, these activities will help you think critically about what kind of planning is necessary before attempting a meaningful research experiment, and will help you be better prepared to succeed with your term project. 
Throughout the course, including the final projects, students are required to keep an individual hard-copy lab notebook. They are encouraged to spend 15-20 min at the end of every lab session writing a couple paragraphs about their experiment that day-what they did, what worked well or not well, what they learned, and next steps. During the lab rotations, notebooks are graded by graduate teaching assistants (TAs) daily and account for $15 \%$ of the total course grade. Notebooks are graded twice during the final projects, which is factored into the overall final project grade. They are graded for completion, formatting, and written conclusions. The projects culminate in a group oral presentation. The final project accounts for $35 \%$ of the overall grade; $15 \%$ of that is the white paper and proposal together, $35 \%$ is for effort and diligence in execution as evidenced by the lab notebook and TAs report on overall effort, and the remaining $50 \%$ is for the quality of the final presentation.

\section{ANALYSIS}

We present the analysis for all three cases together, by category. Within each category, we identify how writing is implemented in each course in order to attend to specific goals. Additionally, in some instances, writing is implemented in a way that reflects a category as a whole (e.g., communication) without targeting a specific goal-we discuss these elements at the beginning of each category section. Figure 2 presents a summary of the goals for writing identified in each case and the various writing assignments and course structures in which those goals are embodied. In this section, we provide an example of how a specific implementation seeks to address each goal and category identified in the data. Critical themes that cut across cases are discussed in Sec. VI.

\section{A. Communication}

Each of the three courses has a general goal of having students develop communication skills. At I1, one of the course objectives is that students will "clearly and convincingly communicate experimental work," in part, through writing. At I2, the syllabus introduces students to the course by stating that there will be an emphasis on "developing good scientific procedures in planning, conducting, recording, and reporting the results of experiments." We interpret both of these statements as signals to students that the course as a whole should help them develop, practice, and/or improve their written communication skills in general. At I1, this general communication goal is reflected specifically in peer review and reflection writing assignments. In the interview, John talks about using peer review as a tool to help students improve their own writing, since the peer-review process "forces them to crystallize a little bit more in a slightly different context what a good proposal looks like, and bring that back to the writing that they do for their own [proposal]." Additionally, the final reflection assignment has students reflect on how they think their communication skills have improved throughout the course. Thus, John strives to help students improve their own writing skills through both review of peers' writing and reflection on their own development. At $\mathrm{I} 3$, the idea of developing general writing skills is evident in the final project rubric, which states that for full points the proposal must be "well written and understandable."

\section{Cohesive narrative}

At I2, Megan has a specific communication goal that students will learn how to write lab reports with a cohesive narrative. In a rubric and guidelines document given to students, which outlines the expectations for what a lab report should look like, Megan writes, "I DON'T KNOW HOW TO STATE THIS STRONGLY ENOUGH BUT YOU SHOULD NOT HAVE A 'DATA DUMP' SECTION. By that I mean don't have a section called "Data and Graphs," where you just put tables, raw data, calculation, graphs, etc...with no narrative. This is very unprofessional and means that a reader has to jump back and forth between your data and discussion." Megan stresses the idea of a cohesive narrative to the students through this guidelines document and in-class discussions.

At I3, we see the cohesive narrative goal evident in the criteria for white papers and proposals. The rubric for both writing assignments includes the question, "Does the paper flow smoothly and is it concise and easy to understand?"

\section{Different modes of communication}

All three courses address the different modes of communication goal since they require students to engage with 4 to 5 different types of writing. A course structure that incorporates multiple types of writing implies that it is important for students to practice writing with different purposes for different audiences. Some courses also connect the different modes of communication goal to the professional practice of scientists; this will be discussed below in the WAP section (Sec. V B 1).

\section{Argumentation}

Argumentation is a major goal of the $\mathrm{I} 3$ course, under both the communication and WAP categories. In particular, they are focused on teaching "persuasive skills" in the context of writing. This is evident in the extensive white paper and proposal process in which students have to write a convincing argument about their proposed project. The white paper and proposal process is intended to support students in developing the general skill of being able to write a clear and convincing argument, as well as teach them about the realistic scientific practice of argumentation. The latter will be discussed below in the WAP section. In this case, the argumentation goal interacts with the 


\begin{tabular}{|c|c|c|c|}
\hline & Case 1 & Case 2 & Case 3 \\
\hline Communication & $\begin{array}{l}\text { Peer review } \\
\text { Reflections }\end{array}$ & & Proposal \\
\hline Cohesive narrative & & Reports & $\begin{array}{l}\text { White paper } \\
\text { Proposal }\end{array}$ \\
\hline Different modes & Course structure & Course structure & Course structure \\
\hline Argumentation & & & $\begin{array}{l}\text { White paper } \\
\text { Proposal }\end{array}$ \\
\hline \multicolumn{4}{|l|}{ Content mastery } \\
\hline \multicolumn{4}{|l|}{ Nature of science } \\
\hline WAP & & & $\begin{array}{l}\text { White paper } \\
\text { Proposal }\end{array}$ \\
\hline Different modes & & $\begin{array}{l}\text { Course structure } \\
\text { Lab notebook } \\
\text { Reports }\end{array}$ & $\begin{array}{l}\text { White paper } \\
\text { Proposal }\end{array}$ \\
\hline Argumentation & Proposal & Proposal & $\begin{array}{l}\text { White paper } \\
\text { Proposal }\end{array}$ \\
\hline Professional norms & $\begin{array}{l}\text { Lab notebook } \\
\text { Reports }\end{array}$ & $\begin{array}{l}\text { Lab notebook } \\
\text { Proposal } \\
\text { Reports }\end{array}$ & $\begin{array}{l}\text { Lab notebook } \\
\text { White paper } \\
\text { Proposal }\end{array}$ \\
\hline Writing as a practice & $\begin{array}{l}\text { Course structure } \\
\text { Lab notebook } \\
\text { Proposal } \\
\text { Reports }\end{array}$ & $\begin{array}{l}\text { Lab notebook } \\
\text { Proposal } \\
\text { Reports } \\
\text { Peer review } \\
\text { Letter to the editor }\end{array}$ & $\begin{array}{l}\text { Lab notebook } \\
\text { White paper } \\
\text { Proposal }\end{array}$ \\
\hline Engaging with lit & $\begin{array}{l}\text { Proposal } \\
\text { Reports }\end{array}$ & $\begin{array}{l}\text { Proposal } \\
\text { Reports }\end{array}$ & $\begin{array}{l}\text { White paper } \\
\text { Proposal }\end{array}$ \\
\hline Nature of science & $\begin{array}{l}\text { Lab notebook } \\
\text { Peer review }\end{array}$ & Peer review & $\begin{array}{l}\text { White paper } \\
\text { Proposal } \\
\text { Peer review }\end{array}$ \\
\hline \multicolumn{4}{|l|}{ WTL } \\
\hline \multicolumn{4}{|l|}{ Content mastery } \\
\hline Reflection & $\begin{array}{l}\text { Lab notebook } \\
\text { Reflections }\end{array}$ & $\begin{array}{l}\text { Course structure } \\
\text { Lab notebook } \\
\text { Letter to the editor }\end{array}$ & Lab notebook \\
\hline Synthesis & & Reports & \\
\hline \multicolumn{4}{|l|}{ Engaging with lit } \\
\hline Nature of science & Course structure & & \\
\hline \multicolumn{4}{|l|}{ Course logistics } \\
\hline $\begin{array}{r}\text { Facilitating the } \\
\text { project }\end{array}$ & $\begin{array}{l}\text { Lab notebook } \\
\text { Proposal } \\
\text { Reflections }\end{array}$ & $\begin{array}{l}\text { Lab notebook } \\
\text { Proposal }\end{array}$ & $\begin{array}{l}\text { Lab notebook } \\
\text { White paper } \\
\text { Proposal }\end{array}$ \\
\hline Grading & Reports & Reports & \\
\hline \multicolumn{4}{|l|}{ Social emotional } \\
\hline Affect & $\begin{array}{l}\text { Reports } \\
\text { Reflections }\end{array}$ & & \\
\hline Agency & $\begin{array}{l}\text { Lab notebook } \\
\text { Proposal }\end{array}$ & Course structure & \\
\hline Identity & $\begin{array}{l}\text { Reflections } \\
\text { Reports }\end{array}$ & & \\
\hline
\end{tabular}

FIG. 2. Implementation of writing to address specific goals for each case. Writing used to address a category overall, but not a specific goal within that category, is indicated in the category heading row. "Course structure" indicates that the goal or category is addressed by the overall structure of the course and not by implementation of a specific writing assignment. 
course logistics goal of facilitating the project-students have to learn how to write persuasively as a general communication skill, but also so they can convince their peers and instructors that they are prepared to do the project and that the project is worth doing.

\section{B. WAP}

Each of the three courses has an emphasis on WAP, due to the advanced lab context and the nature of projects. Most of the WAP goals are present in all three courses. At I2, the statement in the syllabus that the course is intended to introduce "realistic forms of communication" (emphasis added) signals to students that writing in the course will help them learn about, and engage with, professional practice of scientists. At I3, the white paper and proposal process comprises a major part of the course, as evidenced by the fact that one of the four course goals is that students will learn about proposal writing. The framing of the white paper and proposal assignments is centered around the idea that students need to learn about realistic writing practices important to the scientific community.

\section{Different modes of communication}

In the I 2 course, Megan has a general goal of teaching students how to write for different types of audiences, as a part of teaching "professionalism." In future instantiations of the course, once the curriculum has been modified to include two semester-long advanced lab classes, Megan plans to use the extra course time to ask students to present a single experiment in different ways (e.g., through a report and a poster). In the current version of the course, she emphasizes lab notebooks and reports as two important modes of writing in the scientific workplace. "If you work in any technical environment, you need documentation of what you're doing...if [students are] going to be asked to produce a presentation or report, they need to know what they did and what their data is." Thus, she wants students to practice keeping a notebook and using that record to create a summative report, in preparation for their future careers. When asked why she includes lab reports as part of the course, Megan said "its a skill that is realistic that they're going to have to do, is some type of technical writing. It's not always going to be a lab report format." Although the form of technical writing will vary, the report (in a style similar to a journal article) is one thing students can practice in a time-constrained course.

At I3, the instructors highlight two specific modes of communication that are important for scientists' workwhite papers and proposals. Though in the course (and often in real scientific practice) there is significant overlap between a white paper and proposal for a given project, the instructions and guidelines documents given to students distinguish between the two. The intended audience is the same for white papers and proposals (funding agencies in real life, peers and instructors in the course context), but the purpose differs slightly since the white paper acts as a "preproposal" that allows funders (instructors) to "narrow down the projects they are interested in without requiring the researchers to put the effort into creating a longer proposal or the reviewers to examine a longer, more detailed proposal.

\section{Argumentation}

An overall goal of the I3 course is to help students develop their argumentation skills, in the sense that they need to learn how to "sell [their] ideas within a scientific community" and be able to convince others that their work is valuable. At $\mathrm{I} 3$, the argumentation goal (within both communication and WAP) is pursued through the white paper and proposal process. Over the course of several weeks, students have to come up with an idea, construct an argument, and convince their peers and instructors that their project is worth doing, mirroring a realistic scientific funding process. Likewise, both I1 and I 2 include proposals that require students to persuade their instructor and/or peers that their project is interesting and feasible. The I1 syllabus explains to students that their proposals must contain "an argument (as one might see in a funding proposal) for why the proposed project is worth doing." This statement explicitly connects argumentation to professional practice within the scientific community.

\section{Professional norms}

In all three courses, the instructors espouse the notion that students need to learn the professional norms of keeping a lab notebook so that they will be prepared to do research (or engage in some form of laboratory work). Each of the three courses uses a lab notebook rubric that specifies professional norms of what a lab notebook should look like (e.g., notebook entries need to have diagrams and graphs, data must include units, entries must be clear and easy to follow). The fact that instructors incorporate these elements in their grading signals to students that they are important. However, the notebooks are decidedly not graded based on a specific formatting or structure. Matthew does not require specific formatting because he worries that in doing so, students would tend to focus on the superficial details rather than more important contents of the notebook. At I1, the discussion at the beginning of the term about historical examples of lab notebooks is intended to help students understand how they should be using their lab notebooks and the standards that they should adhere to. During a FOLC meeting, John also talked about how grading the notebooks and providing formative feedback throughout the term helped students "internalize...the meaning of having a structured document that they could refer back to."

The I1 and I 2 courses both assign lab reports that are intended to mirror scientific papers. At I1, students read and discuss an American Journal of Physics (AJP) article in 
order to understand what they should (and should not) do in their papers. John also specified that their papers are supposed to have the same tone and level of detail as a scientific article, and the rubric indicates that they should use the Physical Review citation style. At I2, Megan wrote guidelines for students' reports based on how she typically writes journal articles. The guidelines explain what good presentations of data should look like and detail roughly what should be included in each section of a paper, though the rubric states that the only specific section that must be included is an abstract. Students are given a link to Physical Review X and encouraged to look at the articles there to see what an abstract typically looks like. At both I1 and I2, these discussions and guidelines help students learn about the professional norms of writing scientific papers.

Similar to the lab reports, proposals also have professional standards that students are expected to adhere to. In the I2 course, Megan gives students examples of real proposals (from her own research) to help them understand what their proposals should look and sound like. At I3, the guidelines for white papers and proposals explain that these pieces of writing must have "properly documented citations and a bibliography." Students are also instructed on how to include figures: "Figure captions should fully describe the important parts of the figure and do not replace explaining the figure in the text." Additionally, the grading rubric asks, "Is the tone of the paper suitable for an academic or professional audience?" In the I3 course, a good proposal must not only have a convincing argument, but also look and sound professional.

\section{Writing as a practice needed for technical professions}

Across the three cases, the most highly emphasized goal for writing is to give students a chance to engage with writing practices that are common and important in scientific or technical professions. Megan approaches the I2 course as a whole with this goal in mind, saying "I tell my students this "When you get into these industries, you won't believe how much writing you do."' The three instructors address this goal through their implementation of most (if not all) writing assignments in their courses.

The practice of keeping a lab notebook is an obvious and common one that many lab classes seek to address, including all three courses in our case-study analysis. At I1, the discussion of historical lab notebook examples helps to convey this professional practice to students, and according to John, is used as a jumping off point for students to think about the point of the lab notebook document, and how scientists use them (and thus, how students should be using notebooks in the class). Tanner talks about getting students in "the habit of doing lab notebooks...for when they do research." The fact that he talks about helping students developing habits signals that the goal is about writing as a practice.
All three courses also include proposals, in part, because writing (and reviewing) proposals is a realistic scientific practice. At I2, giving students examples of real proposals is intended to help them learn about the realistic proposal process. Additionally, Megan chose to have students write proposals as a group since that is often how scientists write proposals. Likewise, the entire white paper and proposal process at $\mathrm{I} 3$ is designed to give students "insight into how the scientific funding process works." Through both the white papers and proposals, students get to engage in the process of writing and reviewing proposals that is central to many scientific and technical professions.

Lab reports are another form of written communication used to teach students about realistic scientific practice, since at I1 and I2 the reports that students write are in the style of a journal article. At I1, students discuss a contemporary article before writing their own and at I2, the instructions students receive are based on the instructor's own approach to writing journal articles. In both of these instances, the instructors strive to open a window for students into scientific writing practices. Additionally, John talks about the inevitable scenario in which an experiment does not go as planned, but the scientist (or student) has to write a summative final report anyway. He describes this writing practice as a "characteristic of scientific life," saying "you've got these projects. You start them. Maybe they don't go exactly how you think they should go, but nonetheless, the progress, the scientific process, writing new grants, everything depends on you writing reports wherever you got to, and I think that...getting practice...carrying out that skill is one of the main reasons why we do final reports." The goal of teaching students about this characteristic of scientific life also connects to the nature of science goal.

The act of revision and peer review is paramount to the process of science. At I1, at the end of term students have the opportunity to revise and resubmit one of their earlier lab reports. John motivates students to go through this revision process by attaching non-negligible points to it in their grade and said that it has "definitely helped approach the goal of, "This is how we do written communication as experimental physicists." In the $\mathrm{I} 2$ course, the process of peer review is intended to remain true to the typical peerreview process at a journal, including students resubmitting their revised papers with a letter to the editor that details what they changed and why. Megan gives the students the Physical Review Letters (PRL) guidelines for reviewers to follow in order to review their peers' reports and also outlines for the students what a typical peer-review process looks like. She explains, "Whenever you revise a manuscript after peer review, you resubmit it to the journal with a letter to the editor. This letter not only details the changes you made to the manuscript, but why you made them and how they address specific parts of the reviewer reports." This particular goal of teaching students about writing as a practice in scientific professions through peer review and 
writing a letter to the editor is also connected to reflection, as will be discussed below (Sec. V C 1).

\section{Engaging with scientific literature}

The courses in our study have students engage with scientific literature because it is a specific practice and expectation of scientists. In all three courses, the proposal assignment (and white paper, for I3) requires students to read scientific papers and conduct a literature review. In their proposals, students are expected to include background information and connections between their project and previously published work. Requiring students to conduct a brief literature review and include relevant citations in their proposals serves the dual purpose of teaching them an important professional practice and making sure they are prepared to do their project (connecting to the course logistics goal of facilitating the project). The reports at I1 and I2 are also expected to include references to relevant literature, though most of the engagement with literature happens during the proposal process.

\section{Nature of science}

Science advances through the processes of proposals and peer review. In all three courses, peer review is included (for either proposals or reports) to teach students about the nature of the scientific enterprise. At I3, one goal of the white paper and proposal process, as stated in the guidelines document, is to teach students "what kind of planning is necessary before attempting a meaningful research experiment." We see these goals of teaching students about the role of peer review in science and type of planning necessary in experimental physics to be aligned with the goal of giving students opportunities to understand and experience the nature of science.

One major goal that John, Megan, and Matthew discussed during multiple FOLC meetings is that they want students to be recursive with their projects, taking data multiple times and iteratively revising their experiments. That is, they want students to understand and experience the iterative nature of science. Lab notebooks provide a window into students' experimental process during their projects. One way to encourage students to iterate on their projects is to grade the lab notebooks not just for completion, but based on the content and the process that students followed. At I1, John has found that students are responsive to continual formative feedback on their notebooks.

\section{WTL \\ 1. Reflection}

The primary WTL goal that we see in our data is reflection. At I1, one of the four course objectives communicated to students through the syllabus, is to
"Demonstrate the ability to be reflective on the practice of experimental physics." The way students typically demonstrate this reflectiveness is through writing. In the interview, John describes reflection in this context as being both about "reflecting on your own learning process" and more practically figuring "out what's going on in your experiment." In particular, the reflection writing assignments explicitly ask students to reflect on various aspects of their experiences with the labs or final project in the course. Students are told directly that engaging in metacognition is beneficial for learning. The reflection prompts vary each week, often connecting to additional goals in the framework. For example, in the first reflection assignment, students are asked to identify the area in which they feel most confident in their abilities (modeling, analyzing and visualizing data, etc.). This type of reflection may support students' identity development (connecting to the social emotional goal of identity). In other weeks, students are asked to identify problems or challenges they ran into in the lab, strategies they employed to overcome those challenges, and their next steps for making progress on the lab or project. Reflecting on these questions is intended to help students move forward with their experiments (connecting to the course logistics goal of facilitating the project). In some of the reflection assignments, students are also asked to identify a successful moment for their project that week. Helping students focus on the successes (and not only the things that are going wrong) may help to facilitate positive affective responses to the process of experimental physics (connecting to the social emotional goal of affect). DounasFrazer, Stanley, and Lewandowski found that student ownership over projects was characterized by fluctuating emotions in cycles of struggle and success [22]; asking students to reflect on both their struggles and successes may help to facilitate ownership. Lastly, as discussed above in Sec. VA, the final reflection prompt has students reflect, in part, on how their communication skills have improved, connecting the reflection and general communication goals of the framework.

In the I 2 course, Megan also has an overall goal of reflection though it is not stated directly in the course objectives communicated to students. In the interview, Megan discussed the changes she made to the course when taking over for the prior instructor. In order to build in more time for reflection, she included fewer projects, more time for final projects, and more emphasis on writing. One of the writing assignments that Megan identifies as targeting this goal of reflection is peer review of lab reports. When revising their lab reports after review and writing a letter to the editor, Megan wants students "to think a little bit metacognitively...[about] why did they make these changes? Why did they choose to present something this way?" Thus, the peer-review process (in particular, the letter to the editor) is intended to help students engage in reflection around their own experimental work and writing. 
All three courses utilize lab notebooks as a tool for reflection. John describes that one unique aspect of lab note keeping during student-designed projects is that students are forced to write down what they think is happening at every step of the project, even "when the story that they're thinking about isn't totally complete in their head yet." The lab notebook can thus facilitate students' reflection on the process of experimental physics. For all three courses, the rubrics used to evaluate lab notebooks include a reflection requirement. At $\mathrm{I} 3$, notebook entries are supposed to include 1-2 paragraphs about the days experiment. The instructors communicate to the students that "The paragraphs should describe what you are attempting to do, what worked well, what didn't work well, what you learned, what is needed further to finish up (if anything), etc."'

\section{Synthesis}

Megan hopes that writing, regardless of specific type or assignment, can be a tool to help students "understand how to analyze [a] situation." Specifically, she says that the report for the final project should require students to "synthesize what they're doing" and force them to "actually have to think about what [the] analysis means." In assigning lab reports in the I 2 course, Megan wants students to learn "how do you put all these pieces of evidence and all this background, how can that work together for you to draw conclusions?"

\section{Nature of science}

In the framework, the nature of science goal exists in the overlap between the communication, WAP, and WTL categories. In our case-study analysis, we find evidence of NOS related to both WTL and WAP. John describes the purpose of the final projects in the I1 course as giving the students an experience of proposing and carrying out their own specific experiment, including especially "iterating and revising it as they progress." The idea of iteration (including troubleshooting) is also conveyed in the syllabus when the instructor explains to students why they will have two weeks to complete each of instructor-designed labs. "This will give you time to become familiar with the physics you are exploring and the experimental setup, to try taking some data, and to make modifications. If you get data quickly for an experiment, you may want to do some initial analysis and then come back to take additional data." We consider this statement to reflect a WTL nature of science goal because it explains that the iterative process of experimentation will help students learn about both physics content and the experimental setup.

\section{Course logistics}

In each of the three courses, writing plays a practical role in helping the course as a whole, and students' projects specifically, progress.

\section{Facilitating the project}

All three instructors identified both lab notebooks and proposals as playing the role of helping students make progress on their projects. Lab notebooks can help students keep track of what they have done and the data they have collected such that when it is time to create a final report or presentation, all of the necessary information is clearly laid out for them. In all three courses, notebooks are checked periodically (sometimes daily) by instructors or teaching assistants, ensuring that students are using them regularly in a way that will support the forward progress of their projects.

Proposals can facilitate the planning process of projects and help students make sure they are prepared to conduct an interesting and feasible experiment. The instructors from all three courses said that one major reason they include proposals is that they require students to figure out and communicate (to instructors, peers, and themselves) a plan for their project. By requiring proposals, instructors can ensure that students have thought through their project ahead of time and are prepared to carry it out. At I3, the white paper and proposal process is a several week long process that ensures students prepare for their projects in advance. In the interview, Tanner describes how this process successfully facilitates the projects: "the first day of term projects comes along, they've already ordered the equipment they need, they've already done calculations and know what to expect, they've already done designs. And so they can really get going... since we've [included the white paper and proposal process] the projects are much more interesting and they tend mostly to be successful, whereas before they mostly didn't." This goal of proposals also appears in the I3 final project rubric, which includes the statement, "proposal shows that the relevant issues have been thought through and the project has a good starting direction."

At I1, some of the reflection writing assignments are also intended to help facilitate forward progress on the projects. Reflecting on, and writing about, the problems they have encountered, strategies they have tried, and their plans for next steps, may help students continue making progress on their projects even when they experience the inevitable challenges and dead ends.

\section{Grading}

In addition to the variety of benefits that writing reports can provide, John and Megan both include reports because it allows them to assign individual students a grade. As a followup to outlining the major goals for reports (e.g., writing as a practice or professional norms), John said, "There's some other boring answer about me needing to have the information about how they're actually thinking about things in the end." We expect that this is one motivating factor when incorporating writing in many lab classes. 


\section{E. Social emotional}

It was less common for instructors to directly convey social emotional goals (either in the interviews or in direct communication to students through the syllabus or other course materials), but we believe that any physics class can address social emotional factors like affect, agency, and identity. Social emotional goals may be addressed through writing in a variety of ways. In this section, we identify the ways in which these goals may be facilitated through writing in the three courses, though there is not always a specific feature of implementation to point to.

\section{Affect}

When students design their own experiments and have only a few weeks to complete them, there is a chance that the experiment will not go as planned—students might not be able to collect the data they need, things will break, or they will run out of time. John thinks that a summative report can support students emotionally in these instances. $\mathrm{He}$ said in the interview, "I think, emotionally...it's probably important to feel like [the project] came to a conclusion and to actually have good feelings about what it is to be an experimentalist even if the experiment didn't necessarily go as they wanted it to." He suggests that even if students are not able to complete their projects as planned, it is important that they write a summative report about the work that they did do. We interpret this statement as being aligned with the affect goal because John wants the writing to support a positive affective response ("good feelings") among students. This goal also connects to identity development, as discussed below in Sec. VE3. Additionally, one of the reflection prompts during the final project portion of the I1 course asks students to write about a "successful moment when you got something to work (or moved something ahead) for your project." We see this question as potentially supporting a positive affective response or encouraging the aforementioned "good feelings about what it is to be an experimentalist."

Megan identifies positive affect as an overall goal of the projects in her course, saying that "doing your own project should feel fun and rewarding." She also connects this to the aspect of student agency, in justifying the structure of group proposals.

\section{Agency}

In the I 2 course, Megan wants all students to have a choice of their project topic. To that end, she has students first assemble in groups and then select a project topic that all group members are interested in. Through this structure, Megan hopes that every student will have some agency in selecting their project topic.

One unique feature of projects in advanced lab courses, like those in our analysis, is that students get to select, design, and carry out their own project-i.e., they get to make decisions about their project at every step of the process. John notes that in this unique context, the lab notebook is important and meaningful. The process of writing in a lab notebook helps facilitate forward progress on the projects (Sec. VD 1) as it is the avenue by which students make decisions about what to do next and how to overcome challenges. Likewise, John identifies the proposal as facilitating student agency because it is the medium through which students select and pursue their topic. In this way, various modes of written communication can serve to support student experiences of agency.

\section{Identity}

All of our physics courses are potential sites for students' identity development, and advanced lab courses in which students get to design their own experiment may especially support (or inhibit) students' sense of identity as a physicist or an experimentalist. At I1, the first reflection assignment asks students to reflect on their confidence in their own abilities in various areas of experimental physics. This prompt primes students to start the term by thinking about how they may or may not identify with certain aspects of experimental physics. As discussed above (Sec. VE2), John wants students to "actually have good feelings about what it is to be an experimentalist." In this statement, we see a connection between the affect and identity goals. In the course, and specifically facilitated by writing a final report, John hopes that students will have a positive emotional experience related to their own possible identity as an experimentalist.

\section{AFFORDANCES OF PROJECTS}

In our analysis, we see many similarities across the three cases. These three examples point to unique features of student-designed projects in advanced lab courses that allow instructors to address certain goals for writing. In general, this type of project allows for authentic use of multiple types of writing. One key element of multiweek projects is the timescale. Focusing on one experiment for several weeks allows instructors to include peer review (sometimes multiple times) and to expect iteration and revision in students' projects. Additionally, the longer timescale gives the lab notebooks more meaning. Students have to rely on their own documentation practices because by the time they complete the project they will likely not remember the details of what they did several weeks prior [10]. This differs from shorter and more prescribed labs since in those courses students often conduct the experiment and write a report all in one week, and they can rely on a lab manual for any documentation they may have missed.

Beyond the timescale, the nature of the project as a student-driven experiment with no prescribed directions or predetermined outcome presents affordances for focusing 
on WAP. Stanley and Lewandowski [10] suggest that lab activities be designed in a way that requires students to rely on their notebooks, supporting authentic documentation practices. This is certainly the case when students are designing and carrying out their own experiments. Making progress on a project with no prescribed directions may necessitate that students keep a clear and thorough notebook detailing their procedures, goals, plans, and missteps. John discussed this benefit in the interview, saying that the final project "is probably the single point in [the students'] physics education so far, where...lab note keeping is more important than ever. Because they're actually hashing things out on their own, and not following some predefined path where they know that they can coast through certain parts, and that they'll be picked up again when they feel like paying attention again."

A student-designed project allows for, and necessitates, a proposal, providing an opportunity for students to learn about a key aspect of scientific practice. This is particularly true at I3 where students experience the "funding" process. Students have to convince their peers and instructors (through writing) that their proposed project is feasible and worth doing, and that they are prepared to conduct it. This may be the only time in the undergraduate curriculum when students get to meaningfully participate in a proposal process. In all three courses, the proposal structure requires students to engage with scientific literature. For their projects, students may be conducting a novel experiment or replicating and/or modifying a previously published experiment. In either situation, becoming familiar with relevant literature is crucial for the success of students' projects. This gives students an opportunity to learn how to read, evaluate, and critique scientific papers [23].

Through the authentic use of different types of writing, the instructors in our cases strive to teach students the professional norms and conventions for scientific writingprofessional style of writing, appropriate presentation of data and analysis (in a lab notebook or summative report), what should be included in a journal article, the role of an abstract, etc. Some of these are built directly into the courses, through rubrics and expectations set for students, but others may be adopted by students through engaging with literature, reviewing their peers' writing, and participating in in-class discussions around good note keeping or writing practices.

For the courses in our study, and likely many advanced physics lab courses in a variety of contexts, the overall goal of the projects is to prepare students to do research. As such, communication to students around the course and the projects is that they are engaging in the process of experimental physics as professional scientists would. This framing allows instructors to introduce writing as a practice needed for scientific and technical professions. Incorporating authentic forms of writing and continually connecting the writing students are doing back to professional scientific practice allows instructors to address the goal of teaching students about the nature of science. In particular, the opportunity to engage in a peer-review process mirrored after realistic scientific practice can afford students the opportunity to experience how scientific knowledge is generated.

Though the courses in our study emphasize WAP, the open-ended and individualized nature of projects also allows instructors to target goals in other categories. One of the characteristic features of student-designed projects is that they provide ample opportunities for student agencystudents get to select a topic, define a research question, design the experiment, (sometimes) order supplies, and they are responsible for troubleshooting the many unforeseen problems along the way. In the courses in our study, writing is the structure through which students exercise this agency (i.e., they formally select and refine their idea through a proposal, and make plans for next steps in a lab notebook or in reflection writing assignments). In the same vein, writing a paper about a project they have designed and conducted on their own may be more enjoyable than writing a report about an experiment with prescribed instructions that every student in the class has to conduct. As such, student-designed projects allows for writing that may facilitate positive affective responses to experimental physics. We also see possible interactions between the overall WAP approach of these advanced lab courses and the identity goal; being able to learn about and practice scientific writing in an authentic way may help students strengthen their sense of identity as a physicist.

WTL is an approach used in many undergraduate science courses $[14,16]$, but advanced lab projects present a unique opportunity for addressing the goal of reflection in a way that differs from other contexts. Students can reflect on their own learning about the physics content of their project—often a topic their instructor is not an expert in-as well as learning about the process of experimental physics in general. They can also reflect on their own decisions and planning throughout the course of the project-what worked well or not so well, what problems did I encounter, what strategies will I try next time? Noticeably, none of the courses in our study address the goal of content mastery, since the advanced lab courses are more focused on experimental practices and preparing students to be independent researchers. We expect that introductory lab courses more often address content mastery through writing.

All three courses in our study are aligned in addressing the course logistics goal of facilitating the project through lab notebooks and proposals. This goal itself is unique to projects, since each group of students are conducting a different experiment and what progress looks like will vary by project. Instructors in these courses rely on writing 
assignments like proposals and lab notebooks to keep the students on track.

\section{LIMITATIONS}

Our case study approach does not allow for generalization to all advanced lab courses or all courses with multiweek projects. The three case studies are not even meant to define the breadth of possibilities. There are many different ways to incorporate writing into student-designed projects, and many different permutations of goals instructors might have for doing so. The implementation of writing we have described for our three cases exists in specific institutional and course contexts. The multiple case-study analysis is intended to provide researchers and instructors with some examples of how writing can be incorporated as a core element of an advanced lab course and the kinds of goals such implementation of writing can seek to address.

In our case study analyses, we identify the goals for writing, but not whether (or to what extent) the goals were accomplished. Further research is needed to determine if, e.g., including a peer review process in class helps students construct a realistic and nuanced understanding of the nature of science. Along a similar vein, an additional limitation of this study is that it does not include student perspective. We focus on the instructors' perspectives and course materials in order to gain an understanding of the implementation of writing, and do not investigate how students experience or engage with the writing. Including students' perspectives may bring to light additional factors not captured in the present analysis. For a preliminary study of students views about, and experiences with, writing, see Ref. [24].

\section{CONCLUSIONS}

We used our framework of goals for writing in lab classes [5] as a lens with which to investigate implementation of writing in three advanced lab courses with studentdesigned projects. Our multiple case-study analysis provides examples for how writing can be incorporated to address a variety of goals. All three courses in our study include multiple different types of writing assignments, and emphasize WAP in their framing and implementation due to both the advanced lab context and the open-ended nature of projects. Key features of projects such as student agency, longer timescale, and lack of a predetermined outcome allow for authentic use of writing and may support reflection and students' social emotional experiences. This paper provides implementation examples for instructors, and illustrates how the framework can be used as a tool for research.

\section{ACKNOWLEDGMENTS}

We thank the instructors for their partnership on this research project, Dimitri Dounas-Frazer and Laura Ríos for initialization of ideas and data collection that preceded this work, and the CU PER group for useful conversations and feedback. This work is supported by NSF Grants No. DUE1726045 and No. PHY-1734006. Viewpoints expressed here are those of the authors and do not reflect views of NSF.
[1] Joint Task Force on Undergraduate Physics Programs, Phys21: Preparing Physics Students for 21st-Century Careers, Tech. Rep. (American Physical Society and American Association of Physics Teachers, College Park, MD, 2016), ISBN 978-0-9982529-9-5, http://www .compadre.org/JTUPP/docs/J-Tupp_Report.pdf.

[2] J. Kozminski, H. J. Lewandowski, N. Beverly, S. Lindaas, D. Deardorff, A. Reagan, R. Dietz, R. Tagg, M. Eblen-Zayas, J. Williams, R. Hobbs, and B. Zwickl, AAPT Recommendations for the Undergraduate Physics Laboratory Curriculum Subcommittee Membership, Tech. Rep. (American Association of Physics Teachers Committee on Laboratories, College Park, MD, 2014), https://www.aapt.org/Resources/ upload/LabGuidlinesDocument_EBendorsed_nov10.pdf.

[3] B. M. Zwickl, N. Finkelstein, and H. J. Lewandowski, The process of transforming an advanced lab course: Goals, curriculum, and assessments, Am. J. Phys. 81, 63 (2013).

[4] D. R. Dounas-Frazer, L. Ríos, B. Pollard, J. T. Stanley, and H. J. Lewandowski, Characterizing lab instructors' self-reported learning goals to inform development of an experimental modeling skills assessment, Phys. Rev. Phys. Educ. Res. 14, 020118 (2018).

[5] J. R. Hoehn and H. J. Lewandowski, Framework of goals for writing in physics lab classes, Phys. Rev. Phys. Educ. Res. 16, 010125 (2020).

[6] C. W. Keys, B. Hand, V. Prain, and S. Collins, Using the science writing heuristic as a tool for learning from laboratory investigations in secondary science, J. Res. Sci. Teach. 36, 1065 (1999).

[7] J. A. Rudd, T. J. Greenbowe, B. M. Hand, and M. J. Legg, Using the science writing heuristic to move toward an inquiry-based laboratory curriculum: An example from physical equilibrium, J. Chem. Educ. 78, 1680 (2001).

[8] W. B. Lane, Letters Home as an alternative to lab reports, Phys. Teach. 52, 397 (2014).

[9] C. L. Ramey II, The transformation of an upper-division lab and comparative analyses of two scientific writing activities, M.S. Thesis, Texas Tech University, 2018. 
[10] J. T. Stanley and H. J. Lewandowski, Recommendations for the use of notebooks in upper-division physics lab courses, Am. J. Phys. 86, 45 (2018).

[11] J. Kozminski and M. Masters, Journal of the Advanced Physics Laboratory Investigation (JAUPLI): User's Guide, in Workshop, American Association of Physics Teachers Conference on Laboratory Instruction Beyond the First Year (American Association of Physics Teachers, College Park, MD, 2015).

[12] M. Eblen-Zayas, The impact of metacognitive activities on student attitudes towards experimental physics, in Proceedings of the 2016 Physics Education Research Conference, Scaramento, CA (AIP, New York, 2016), pp. 104-107, https://doi.org/10.1119/perc.2016.pr.021.

[13] T. Feder, College-level project-based learning gains popularity, Phys. Today 70, No. 6, 28 (2017).

[14] C. Moskovitz and D. Kellogg, Inquiry-based writing in the laboratory course, Science 332, 919 (2011).

[15] L. O. P. Rivard, A review of writing to learn in science: Implications for practice and research, J. Res. Sci. Teach. 31, 969 (1994).

[16] J. A. Reynolds, C. Thaiss, W. Katkin, and R. J. Thompson, Writing-to-learn in undergraduate science education: A community-based, conceptually driven approach, $\mathrm{CBE}$ Life Sci. Educ. 11, 17 (2012).

[17] D. R. Dounas-Frazer and D. L. Reinholz, Attending to lifelong learning skills through guided reflection in a physics class, Am. J. Phys. 83, 881 (2015).
[18] S. B. Merriam, The case study in educational research: A review of selected literature, J. Educ. Thought 19, 204 (1985), https://www.jstor.org/stable/23768608.

[19] M. Eisenhart, Generalization from qualitative inquiry, in Generalizing from Educational Research: Beyond Qualitative and Quantitative Polarization, edited by K. Ercikan and W.-M. Roth (Routledge, New York, NY, 2009), Chap. 4, pp. 51-66.

[20] M. Dancy, A. C. Lau, A. Rundquist, and C. Henderson, Faculty online learning communities: A model for sustained teaching transformation, Phys. Rev. Phys. Educ. Res. 15, 020147 (2019).

[21] J. R. Taylor, An Introduction to Error Analysis: The Study of Uncertainties in Physical Measurements (University Science Books, Sausalito, CA, 1997).

[22] D. R. Dounas-Frazer, J. T. Stanley, and H. J. Lewandowski, Student ownership of projects in an upper-division optics laboratory course: A multiple case study of successful experiences, Phys. Rev. Phys. Educ. Res. 13, 020136 (2017).

[23] C. M. Gillen, Criticism and interpretation: Teaching the persuasive aspects of research articles, CBE Life Sci. Educ. 5, 34 (2006).

[24] J. R. Hoehn and H. J. Lewandowski, Investigating students' views about the role of writing in physics lab classes, in Proceedings of the 2020 Physics Education Research Conference (AIP, New York, 2020), pp. 216-221, https:// doi.org/10.1119/perc.2020.pr.hoehn. 